\title{
WATER MANAGEMENT PLANS IN PANAMA: FROM IWRM TO WATER SECURITY
}

\author{
VALEIRY ADJANY VEGA CERVERA \\ Instituto Universitario del Agua y de las Ciencias Ambientales, University of Alicante, Spain
}

\begin{abstract}
Water management in Panama presents numerous existent issues related to increasing water demand, cities suffering from water stress and droughts annually, limited access of water and sanitation on areas, holding back economic and social growth of the population, water leakages in the potable water distribution systems, water pollution and degraded natural systems. The circular economy strategy proposes researchers to reconsider current models, which in aspects of water the challenge lies in managing this resource well, as it is a key component in human activities, industrial processes and agriculture. In the case of Panama, water is also critical resource for the operation of the Panama Canal, as well as energy generation, the two major water users in the country. The Ministry of Environment published in 2010 the National Integrated Water Resources Management Plan 2010-2030 with the objective of guiding actions towards the best use, protection and conservation of the natural resource. However, through the passing of an extensive drought event on 2015 that caused alarm at national level due to shortages of water and energy, a new plan was devised to address the issues thus the "National Water Security Plan 2015-2050: Water for all" was born. This paper will use a comparative method to analyze the changes that the country is going through in terms of water management plans and concepts: from Integral Water Resources Management (IWRM) Plan to Water Security Plan. The study will identify the gaps in the old plan and how they are planned to be filled by the new document, factors that led to its replacement and what potential links of circular economy strategies could be researched in the future to strengthen the National Plan.
\end{abstract}

Keywords: water security, IWRM, water management plan.

\section{INTRODUCTION}

The Republic of Panama limits to the North and the South with the Caribbean Sea and the Pacific Ocean, respectively. The country's extensive water network is integrated by 52 hydrographic basins and 500 rivers that in their great majority are born in the continental divide and drain to the coasts. On the Atlantic side, which occupies about $30 \%$ of the national territory, 18 hydrological basins are located with 150 rivers characterized by their short route and high slope; the other 34 hydrographic basins and 350 rivers are located on the Pacific slope with an average length of $106 \mathrm{~km}$ and slope of $2.27 \%$ [1]. Rainfall events in Panama are characterized by being very intense and of short duration, this produces annual average values between $1,000 \mathrm{~mm}$ and $7,000 \mathrm{~mm}$, but their distribution generates well defined areas in the country with more or less precipitation [2]. For example, the provinces located in the region known as the Panama Dry Arc (Arco Seco of Panama), are characterized by suffering water deficits annually during the dry season and prolonged drought periods, which extend up to seven months with the occurrence of the phenomenon of El Niño. This region of important agricultural vocation for the country is where the lowest rainfall totals of the year are registered with annual values lower than $1500 \mathrm{~mm}$ [2].

The main water uses in Panama are the generation of electricity (around $16,000 \mathrm{Mm}^{3}$ per year), and the operation for Panama Canal locks (2580 $\mathrm{Mm}^{3}$ per year), followed by public supply water use (approximately $733 \mathrm{Mm}^{3}$ ) and water use for irrigation (405.6 million $\mathrm{m}^{3}$ ) [3]. The Panama Canal is one of the main routes of world trade that unites the Atlantic and Pacific oceans and it is one of the engines of the country's economy. For the 2017 fiscal 
year, the Panama Canal Authority (ACP) provided contributions to the National Treasury for $\mathrm{B} / .1,650$ million [4], generating an important percentage of the economic category of transportation, storage and communications, one of the largest contributors to the 10,042 million dollars of the Panamanian Gross Domestic Product (GDP) for the third quarter of 2017 [5].

In a country widely dependent on water resources as a key part of its economy, recurrent limitations in water management have been identified over the years, such as a fragmented sectoral approach and few experiences of inter-institutional coordination, water resources deterioration in watersheds throughout the country, especially in the capital city, limited role of civil society in the management of water resources, lack of resources for the compliance monitoring and control of existing water regulations and technical norms, disorderly urbanization processes in sectors of the country and expansion of improvised settlements in some cases, among others.

During the last years, the country has been going through the process of reforming legislation, initiatives and practices for water management. These have arisen from the need to respond to crises caused by the El Niño phenomenon and the growing concern to regulate the availability of water in the areas mentioned as the Arco Seco and secure the capacity to satisfy future demands of the recently expanded Panama Canal. The operation of the recently inaugurated Panama Canal expansion is expected to increase water availability needs in the future, added to the demand forecasts of the populations of Panama City and West Panama that are supplied by the same lakes used for the operation of the Panama Canal. Several studies have been carried out in the past and are continued to be carried out on alternative water sources in watersheds near the Panama Canal, specifically in the Indio River Watershed.

One of these reforms, which will be the object of study of this article, is the replacement of the National Plan for Integrated Management of Water Resources 2010-2030 for the National Water Security Plan 2015-2050: Water for All created through the Resolution of Cabinet No. 114 of August 23rd, 2016.

\section{THE NATIONAL PLAN FOR THE INTEGRATED MANAGEMENT OF WATER RESOURCES (PNGIRH) 2010-2030}

Practices related to the concept of Integrated Water Resources Management (IWRM) has been the reference point over the past decades in the discursive framework of international water policy [6].

In Panama, the concept of Integrated Water Management was adopted through the Executive Decree $\mathrm{N}^{\circ} 84$ of April 9th, 2007 by which the National Policy of Water Resources was approved. It's principles, objectives and lines of action were aimed at guiding the activities to be developed in public institutions and Panamanian society regarding the promotion of the integral water resource management concept [7].

As part of the strategy for the implementation of the National Water Resources Policy, the National Environmental Authority (ANAM) now Ministry of Environment (MiAmbiente), published in 2010 the National Integrated Management Plan for Water Resources 2010-2030 approved by Resolution of the National Environmental Council CNA002-2012, with the aim of being a reference tool for public, private or mixed development plans, to be developed in the context of the country's watersheds under the responsibility of ANAM.

In order to develop the Plan, a multidisciplinary team of consultants was hired in the areas of evaluation (water balances), planning, water resources economics and institutional and financial aspects. During the process of preparing the plan, participatory and consultation 
processes were developed with different key actors at the national and regional levels, both for the review of the studies carried out, and in the definition of the objectives and strategic guidelines of the Plan [8].

The PNGIRH had a planning horizon up to 2030, with proposals for medium and longterm programmatic actions and two stages, the first stage (2010-2014) which included different actions related to each of the strategic axes and its own projects to be executed by each institution. In the second stage (2015-2030), actions that were considered in the Plan as more complex in the long term are incorporated, however there were no defined projects for these later years.

The Plan is structured in five strategic axes, with 129 programmatic actions. The strategies in broad context are presented below:

\section{Strategic axis 1: sustainability of water resources}

- Develop watershed conservation and restoration programs and projects, with an ecosystem and participatory approach.

- Strengthen programs of supervision, control and environmental control for the prevention and control of pollution of water resources.

- Strengthen the Environmental Quality Laboratory (ANAM) in its physical, technical and financial capacities for the effective exercise of its functions.

- Promote the activities of cleaner production $(\mathrm{P}+\mathrm{L})$ for the prevention of pollution in water sources, originated by the productive processes.

- Implement an action plan to achieve total sanitation coverage, inducing the sustainability of services.

\section{Strategic axis 2: water and development}

- Develop comprehensive programs that increase and incentivize productivity and efficient use of water resources.

\section{Strategic axis 3: water and society}

- Develop a continuous and systematic process of formal environmental education at all levels that contributes to the conservation and sustainable use of water resources.

\section{Strategic axis 4: vulnerability and climate change}

- Apply mechanisms of adaptation to climate change.

- Apply mechanisms to mitigate climate change.

\section{Strategic axis 5: institutionality and governance}

- Modernize the legal and institutional framework of the water resource, to promote the total consolidation of the institutions.

- Develop timely, reliable and affordable information systems that favor a high capacity for negotiation and consensus among the different social actors.

The National Plan for Integrated Water Resources Management (PNGIRH) conceptualized that only through IWRM was it possible to integrate water management into economic, social and environmental development and its approval sought to guide actions 
aimed at better use, protection and conservation of the natural resource. It provided for revisions and updates every five years [8].

The implementation of the strategic plan was the responsibility of ANAM being the institution in charge of leading the process of strategic planning of water resources, in coordination with the institutions with competence over them. The Directorate of Integrated Management of Hydrographic Basins (DIGICH) would be in charge of implementation, monitoring, however the PNGIRH did not establish a formal follow-up process or monitoring indicators.

3 NATIONAL WATER SECURITY PLAN (PNSH) 2015-2050

In 2015, the El Niño phenomenon produced the occurrence of one of the largest water crises in recent years, affecting heavily the provinces of Herrera and Los Santos in the "Arco Seco" and provoking alarm nationwide due to the low level of reservoirs, used for electric power generation and human consumption. The situation placed in the focus of the media and citizenship, the management capacity of the resource by the state and the Ministry of the Environment.

As a result of this problem, the Cabinet Council approved the Cabinet Resolution No. 84 of August 11th, 2015, which declared a state of emergency for 60 days, as well as established a High Level Commission with representatives of all competent ministries, to prepare and present a "National Water Security Plan 2015-2050: Water for all" that should incorporate the necessary actions to increase the country's water security and reduce the impacts related to the increase in the frequency and intensity of the phenomena related to climate change in all river basins in the framework of the current Strategic Government Plan 2015-2019.

The PNSH: Water for all, was prepared and presented to the Cabinet on January 19, 2016. From February 24 to March 31, 2016, with the support of the United Nations Development Program, the consultation process was carried out at a national level with the intention of enriching and validating the challenges and the goals framed in the Plan. The PNSH was finally approved by the Cabinet Resolution No. 114 of August 23rd, 2016.

For the implementation of the Plan, the National Water Council (CONAGUA) was created as the entity in charge of promoting, guiding, coordinating and guaranteeing the development and implementation of the National Water Security Plan 2015-2050: Water for All, which will be confirmed by: The Minister of Environment, who will preside over it; or the viceminister in the absence of the minister, the Minister of Economy and Finance, the Minister of Health, the Minister of Agricultural Development, the General Administrator of the Panama Canal Authority, the General Administrator of the National Public Services Authority, the Director of the Institute of Aqueducts and Sewers and the Minister of the Presidency or who they designate.

The National Water Security Plan is comprised of 5 defined goals and projects distributed in the short term (2015-2020), medium term (2021-2030) and long term (2031-2050) for its execution. It constitutes a catalog of 560 projects related to goals under the concept of water security. The general frame of goals their specific related actions are presented below:

Goal No. 1: Universal access to quality water and sanitation services

1. Improvements in the efficiency of drinking water and sanitation services

2. Increase in the coverage of drinking water services

3. Increase in basic sanitation coverage

4. Planning of water and sanitation demands at national and local level 
Goal No. 2: Water for inclusive socioeconomic growth

1. Management of water resource availability

2. Freshwater demand management

3. Increase in freshwater availability

Goal No. 3: Preventive management of risks related to water

1. Preventive risk management

2. Monitoring or early warning of risk

Goal No. 4: Healthy watersheds

1. Integrated watershed management

2. Strengthening water quality monitoring

Goal No. 5: Water sustainability

1. Agreement on water

2. Updating the regulations

3. Institutional strengthening

4. Education and research on the sustainable use of water resources

The same resolution that created the National Water Council (CONAGUA) establishes the creation of its Technical Secretariat [9]. This newly created figure of the Technical Secretariat for Water Security is the entity in charge of following up and making operational the actions framed within the Plan. The Technical Secretariat is attached to the the Directorate of Integrated Management of Hydrographic Basins (DIGICH) of the Ministry, and the Ministry of the Environment is in turn the coordinator of the National Water Council.

The implementation of the PNSH is in its first stages and monitoring indicators are pending to be developed in 2018. The report of plan management for its first year was prepared on December 2017 and is pending to be made public on the CONAGUA website [10].

So far one of the most important tasks carried out by CONAGUA in its initial phase of existence has been related to start up processes of coordination and planification with the water competent institutions [10]. Among the projects already in execution they had provided follow-up to the Panama Canal Authority (ACP) in the pre-investment studies carried out corresponding to reservoirs, water balances, flow calculations ecological and baseline for the Indio River Basin. The construction of a reservoir and a transfer from the basin of the Indio River is considered as the most studied alternative as a source of water for the operation of the expanded canal and drinking water supply of the population of the Provinces of Panama and Panama West. Pre-investment studies will also be carried out for the construction of multipurpose reservoirs in Lake Bayano, Santa María River, Perales, Parita, Ocú and La Villa.

\section{DISCUSSION}

The qualitative review conducted of the programmatic actions of the PNGIRH and the PNSH, have shown that 81 of the strategies established in the former plan have carried on in the new one. The table below illustrates the number of strategic actions that were established in the 
PNGIRH that have been embedded in the projects created to achieve the five goals of the new national plan.

In a way the strategic approach of the PNGIRH can be seen as a first attempt to try to give the direction towards water management wanted to go in the country, and the PNSH has in turn taken the approach of proposing how to get there via the defined projects that are framed in the Plan.

Strategies not continued in the new plan were identified as well, that could be researched to determine if they are convenient to consider into the new Plan, as presented next:

- Consolidate the hydrographic basin as a basic unit of territorial planning, in all State dependencies.

- Review and update regulations that regulate the ecological flow.

- Identify, design and elaborate environmental indicators to measure the effectiveness of supervision, control and inspection tasks related to water resources.

- Expand the coverage of the water balances to the 51 hydrographic basins.

- Establish an incentive mechanism for the reuse of water.

\subsection{Gaps in the Implementation of PNGIRH}

Aside the short amount of years of existence of the PNGIRH, that were not enough to yield significant changes in water management scopes in the country, many factors were identified as gaps towards the implementation of the Plan as follows:

\subsubsection{Lack of follow up process and monitoring indicators}

Activities related to the Integrated Management of Water Resources were carried out during the years in which the PNGIRH was in force, for example, an strategic objective of the Ministry of Environment is to promote the integrated management of watersheds, for which various ecosystems reforestation and restoration projects were executed as part of the regular defined functions of the Directorate of Integrated Management of Hydrographic Watersheds (DGICH) [11]. However, the previous PNGIRH did not establish a follow-up process, so there is no documentation or specific results reports on the plan to monitor the achievement of programmatic actions and verify its implementation of projects not only of MiAmbiente but of the other competent institutions through the plan in the years in which it

Table 1: PNGIRH strategic actions embedded in PNHS goals.

\begin{tabular}{|l|c|}
\hline PNHS goals & PNGIRH strategic actions been continued \\
\hline $\begin{array}{l}\text { Goal 1: Universal access to quality water } \\
\text { and sanitation services }\end{array}$ & 7 \\
\hline $\begin{array}{l}\text { Goal 2: Water for inclusive } \\
\text { socioeconomic growth }\end{array}$ & 25 \\
\hline $\begin{array}{l}\text { Goal 3: Preventive management of risks } \\
\text { related to water }\end{array}$ & 8 \\
\hline Goal 4: Healthy watersheds & 19 \\
\hline Goal 5: Water sustainability & 22 \\
\hline Total & 81 \\
\hline
\end{tabular}


was in force. There were also no monitoring indicators in this regard [12], so there is ambiguity in being able to identify which programmatic actions of the Plan were carried out and which were not.

\subsubsection{Lack of interinstitutional coordination initiatives}

Similarly, the PNGIRH did not establish an inter-institutional coordination mechanism defined for the joint work and monitoring of the established projects of all the competent institutions.

\subsubsection{Divulgation and promotion of the plan}

The Plan did not have a wide dissemination at national and institutional level required to promote it through the public entities, nor it was considered a priority of the State, hence it was relatively unknown [10].

In addition, the following were identified as recurring factors that affected the water related initiatives by the National Environmental Authority (ANAM), now Ministry of Environment (MiAmbiente) including the recent years where the PNGIRH was in force:

- Deficiencies related to budget lines: The institution does not have enough financial capacity to face the water responsibilities assigned. The funds requested by the institution are often cut during the annual budget allocation, a situation related to not being aware of the importance of them. In this sense, the lack of interest or political will to achieve the environmental objectives of the state causes limitations in their management [12].

- To fulfil with their regulatory compliance oversight responsibilities, MiAmbiente does not count with the necessary equipment and instrumentation. The Ministry only possess a single raw water quality laboratory, it was planned to construct a new one but wasn't possible due to restrictions on allowed budget for the installation and operation of the equipment [12].

- Lack of a water value and conservation conscience in society, general public does not act on see that it is a finite resource, the value it must have.

- Missing hydrological data for watershed management. The Electric Transmission Company, S.A. (ETESA) possess a network of meteorological and hydrological stations that are managed with a vision directed to the electric sector and data is available for the Ministry of Environment, but it is not sufficient in all watersheds. On the other hand, the Ministry doesn't possess related trained personnel or area solely dedicated to the acquisition and maintenance of data [12].

\subsection{Advantages identified in the PNSH}

In comparison to the previous plan the new Water Security Plan has advantages that seek to resolve the gaps found in the PNGIRH which will be discussed below:

\subsubsection{Water Security Concept}

In recent years, the United Nations UN-Water organization has promoted the concept of "water security" and defines it as "the capacity of the population to safeguard sustainable access of water in quantity and quality suitable for livelihoods, human well-being and socioeconomic development, to guarantee protection against water-borne pollution and water- 
related disasters, and to conserve ecosystems in a climate of peace and political stability" [13].

CONAGUA considers one of the greatest strength of the Plan that it is based on a more solid concept as water security [10] that has delimited five specific, clear goals for the country, as well as a separation of the objectives and approach required to achieve them. The previous plan in turn, used strategy lines that gave way to a more ambiguous and less concise approach.

The concept also offers the opportunity to harmonize sectoral policies towards a single vision, which could allow breaking with the historical tendency to manage water sectorally by concentrating efforts on a tangible goal. The concept has the capacity to attract political interest, so necessary and often insufficient to raise the relevance of the topic to the State agendas and, consequently, to the budgetary allocations [14].

\subsubsection{Diffusion and impulse}

One of the greatest advantages of the current Plan is its diffusion at the national and institutional level. It has been divulgated and welcomed by the state and government, which provides the impulse of giving water management a priority nature, seen in the development and early implementation phases of the Plan. Likewise, the creation of a new entity such as CONAGUA and its technical secretary were made following the objective to ensure the implementation of the Plan. This responds to the fact that as a country there is a greater awareness of the need for adequate water management due to the strong role it plays on the economic development of the country [10].

\subsubsection{CONAGUA and its technical secretariat}

CONAGUA is a coordinating body, chaired by MiAmbiente and made up of all the institutions with competence in water resources. The technical secretariat of CONAGUA monitors the execution of the Plan's projects that corresponds to the ministry of environment as well as all other institutions, in order to ensure fulfillment of the duties established in the document. Its relationship with MiAmbiente is that of being an instance attached to the Directorate of Integrated Watershed Management (DGICH) with its own separate structure and personnel. Currently, they function as a DGICH project, with temporary staff. The secretary nevertheless hopes to eventually become an independent entity or attached to the ministry of the environment, but with greater independence. Currently all internal procedures such as purchases, forms, etc. It is done through MiAmbiente, due to its nature as a project [10].

The institutions maintain communication with the technical secretariat of how they are executing the projects and currently meet with a monthly frequency. It should be noted that CONAGUA does not implement the projects, it is implemented by the executing institutions which are also in charge of obtaining the financement in their budgets for the projects they proposed for the Plan [10].

\subsection{Challenges for water management in the near future}

Water security as a framework provides a vision, final objective or particular status, while the IWRM approach focuses its attention on the process [15]. In Panama, a country where there has been a growing awareness of the vulnerability caused by the El Niño phenomenon in the natural reserves, the prospects of future water demand in all sectors and the economic 
interest of the country to maintain the water consumption regime of the expanded channel to generate income, the concept of water security has been valuable to outline the management of water with a goal.

The concept carries a defined objective that drives action, with water security being the level to which the state can aspire to reach through the use of integrated water resources management processes. These IWRM processes, however, are not a simple task, since they refer to a relationship between a natural system and a social system, both characterized by being dynamic, which require immediate actions and their results can be visualized in the medium and long term [14].

Nevertheless, IWRM has also been a useful concept in the country to channel the roads and raise awareness of the importance of the action and harmonization of the different sectors with respect to water management. However, the experience of the IWRM plan indicated an ambiguity regarding the integration actions required to be carried out. Similarly, a consistent effort was not achieved to integrate all the competent institutions in the subject.

It should be noted that the concept of IWRM and its application at the basin level is still maintained as the policy and its application at the local level is being carried out through the initiative of the DGICH of the establishment of watershed committees, currently having 14 committees in their initial phases. The integral management of water resources is not only a matter of water, but also of land issues and territorial ordering within a hydrographic basin. However, this application still has a lot of challenges and limitations in the Panamanian context. The concept of basin identification as a management and environmental planning unit is still foreign in Panama, both for institutions with water-related functions and for society in general. The design of a strategy for its true adoption and application in the country is currently needed. Even the water security plan is not focused on watersheds but on the political division of the provinces, which is the administration and planning method used by all the other competent institutions, and the focus and follow-up of the Plan through CONAGUA is also been carried out by measuring percentages of projects executed by Provinces instead of watersheds [16].

The United Nations Report on the Development of Water Resources in the World [17] has criticized that the IWRM approach has been more geared towards economic efficiency than towards equity, sustainability with the environment and adaptation of measures to strengthen social, administrative and political responsibility. These criticisms of the IWRM approach also reflect the situation of water management in Panama where initiatives and the impulse for water management have historically always been driven and have gained more support being related to the economic needs of the country, especially to the operations of the Panama Canal. However, it remains a pending task to work to maintain the same political will to give priority and urgency to the attainment of the human right to access to drinking water and sanitation and to environmental conservation issues to guarantee the availability of the resource.

On the other hand, the success of the implementation of the PNSH will also be related to promoting the awareness that these actions respond to necessary measures for the country and not just an initiative of the current government, to avoid that in the long run the plan would disappear as a temporary project. The maintenance of the processes initiated and their follow-up to identify opportunities for improvement bring to the fore the relationship between politics and water management in the country. The continuation of the Water Security Plan will depend on the political work so that the next governments also adopt the plan, so the technical secretariat of CONAGUA is already foreshadowing the need to develop a lobby strategy to approach municipalities, political parties, etc. to raise awareness of the need of the PNSH as a state initiative [10]. 
Likewise, for the technical secretariat of CONAGUA its biggest challenge is to achieve a permanence as an entity, for this they are working to achieve a mandate under the new water law [10] which is proposed to replace the current law which dates from the $60 \mathrm{~s}$. It will be delivered for review and discussion to the Population and Environment Commission of the Legislative Assembly in mid-January 2018.

Despite the short amount of time of existence, the water security approach can be seen as promising in the country, but its success will have to be supported by a strong effort of seeking the implementation of integrated water management practices. Good governance characteristics of accountability, participation, rule of law, transparency, responsiveness, equity, inclusiveness, effectiveness and efficiency [18] are needed to be fostered as well so they can function as the pillar for water management to procure its continued application in the future.

Some of the main actions identified to promote the capacities related to the implementation of the PNSH to be considered are presented next:

- Ensure the necessary budgets so that the competent institutions in water issues are able to face the responsibilities acquired.

- Promote the importance and interest of the topic in the country and society's agenda.

- Establish results indicators for the National Water Security Plan pending to be developed in 2018 [10].

- Establish transparency and citizen participation mechanisms since CONAGUA's focus lies towards the inter-institutional sector.

- Research of new strategies that allow the implementation of an integrated management of water resources at all levels in an effective and participatory manner according to the national context, as well as good governance practices in water resources competent institutions.

\subsection{Circular economy prospects in water management}

The concept of circular economy is based on three key principles: Principle 1: Preserve and improve natural capital by controlling finite stocks and balancing the flows of renewable resources. Principle 2: Optimize the yields of resources by circulating products, components and materials to the maximum utility at all times in both technical and biological cycles and Principle 3: Promote the effectiveness of the system by revealing and designing negative externalities [19].

In a circular economy, consumption only happens in effective cycles, where resources are regenerated in the biological cycle or recovered or restored in a technical cycle. In the biological cycle, a circular economy encourages the management of biological nutrient flows so as not to exceed the carrying capacity of natural systems and aims to improve the stock of natural capital by creating the conditions for regeneration [19].

In this regard, for Panama the links between water management and the circular economy could be investigated and promoted in various ways:

- Principle 1 regarding preserving and improving natural capital has a special resonance with the reality of current water management in the country given the importance of maintaining a balance between consumption and the capacity for regeneration and conservation of the ecosystems that host the water sources. While it is true that alternatives for regulating the resource through the construction of infrastructures such as multi-purpose reservoirs or reservoirs may be feasible, 
alternatives should continue to be investigated to ensure the ability to guarantee supply not only by engineering means but also respecting naturalness of ecosystems. Research will be important to maintain the availability of the resource without becoming a burden on the ecosystems that host it, for example studies of ecological flow, biodiversity and the promotion of initiatives for its conservation.

- Help in the management of consumption including citizen participation by raising awareness of water saving measures and efficient consumption with a view to creating a water culture more compatible with the needs of the country.

- The discharge of untreated wastewater is also a pending situation to address in all aspects, from the construction of the necessary infrastructure for the processes of enforcement of the regulations established in Panama for compliance with permissible limits of pollutant parameters in discharges of residual water to bodies of water.

- The circular economy also implies an application of systemic thinking: the management of water resources must be approached with a holistic and systemic mentality [20]. In this sense, research on issues of integral management of the resource in Panama should continue to explore mechanisms and administrative, social and technical procedures that are more effective and applicable in the national context in terms of managing the resource from its catchment to its discharge into the natural environment.

\section{REFERENCES}

[1] Ministerio de Ambiente de Panamá, Plan Nacional de Seguridad Hídrica 2015-2050: Agua para todos, 2016.

[2] ANAM, Atlas Ambiental, p. 26, 2010.

[3] GWP Centroamérica, Situación de los Recursos Hídricos en Centroamérica, pp. 10 14, 2015

[4] Autoridad del Canal de Panamá. http://micanaldepanama.com/aportes-del-canal-depanama-al-estado-ano-fiscal-2017/. Accessed on: 6 Jan. 2018.

[5] Contraloría General de la República-Instituto Nacional de Estadística y Censo. https://www.contraloria.gob.pa/inec/publicaciones/Publicaciones.aspx?ID_SUBCAT EGORIA=26\&ID_PUBLICACION=845\&ID_IDIOMA=1\&ID_CATEGORIA=4. Accessed on: 6 Jan. 2018.

[6] Conca, K., Expert networks: the elusive quest for integrated water resources management. Governing Water: Contentious Transnational Politics and Global Institution Building, ed. K. Conca, MIT Press: Cambridge, MA, pp. 123-165, 2006.

[7] Ministerio de Economía y Finanzas, Decreto Ejecutivo No 84 de 9 de Abril de 2007 "Por el cual se aprueba la Política Nacional de Recursos Hídricos, sus principios, objetivos y líneas de Acción,” 2007.

[8] ANAM, Plan Nacional de Gestión Integrada de Recursos Hídricos de la República de Panamá (2010-2030), 2011.

[9] Cabinet Council, Cabinet Resolution No. 114 of August 23rd "that approves the National Plan for Water Security and establishes the National Water Council and the Technical Secretariat", 2016.

[10] Morán, M., Personal communication, National Water Council Technical Secretariat Coordinator, 28 Dec. 2017.

[11] ANAM, Memoria 2014, 2014. 
[12] Mojica, K., Personal communication, Head of Watershed Department of Directorate of Integrated Management of Hydrographic Watersheds of Ministry of Environment, 11 Dec. 2017.

[13] UNESCO.UN-Water, Water Security and the Global Water Agenda, 2013

[14] CATHALAC, Seguridad Hídrica y Cambio Climático, un estudio comparativo del estado de derecho y la gestión del agua, desde lo internacional a lo local, pp. 25-30, 2015.

[15] Cook, C. \& Bakker, K., Water security: Debating an emerging paradigm. Global Environmental Change, pp. 94-102, 2012.

[16] CONAGUA, Informe de Gestión, p. 5 (forthcominig).

[17] United Nations World Water Assessment Programme (WWAP), The United Nations World Water Development Report 2015: Water for a Sustainable World, 2015.

[18] UNESCAP, What is good governance? 2011. http://www.unescap.org/pdd/prs/ ProjectActivities/Ongoing/gg/governance.asp. Accessed on: 6 Jan. 2018.

[19] Ellen MacArthur Foundation, Delivering the Circular Economy. A Toolkit for Policymakers, pp. 22-25, 2015.

[20] Jeffries, N., Applying the circular economy lens to water. http://circulatenews.org/ 2017/01/applying-the-circular-economy-lens-to-water/. Accessed on: 15 Dec. 2017. 